\title{
PERSPECTIVA GLOBAL DE LAS IMÁGENES PUBLICADAS EN MANUALES DE EDUCACIÓN FÍSICA
}

\author{
PERSPECTIVA GLOBAL DAS IMAGENS PUBLICADAS EM MANUAIS DE \\ EDUCAÇÃO FÍSICA
}

\author{
GLOBAL PERSPECTIVE OF IMAGES PUBLISHED IN PHYSICAL EDUCATION \\ TEXTBOOKS
}

Irene Moya-Mata*, Concepción Ros Ros**, Cristina Menescardi Royuela**

Palabras clave

Educación Física.

Educación Primaria.

Imagen corporal.

Estereotipo.

\begin{abstract}
Resumen: El presente trabajo tiene como objetivo determinar el tratamiento dado a las imágenes relativas al cuerpo y a la actividad física presentes en los libros de texto de Educación Física en la etapa de Educación Primaria. La muestra está constituida por 997 imágenes de nueve libros de texto publicados por cinco editoras. Se realizó un análisis descriptivo de las variables sexo, edad, raza y somatotipo referentes al cuerpo, y las variables tipo, ámbito, espacio y nivel de práctica referentes a la actividad física. Los resultados muestran que se mantienen los estereotipos relativos al cuerpo y actividad física, enfatizando el cuerpo masculino, de raza blanca, con un cuerpo delgado y cuya edad es la infancia, practicando deportes y habilidades motrices. Sin embargo, el ámbito y nivel de práctica de actividad física elitista han desaparecido de los manuales, mostrando un primer paso hacia la diversificación de actividades físicas en la escuela.
\end{abstract}

Palavras-chave Educação Física. Ensino

Fundamental. Imagem corporal. Estereotipagem.

Keywords Physical Education. Primary Education. Body image. Stereotyping
Resumo: 0 presente trabalho tem como objetivo determinar 0 tratamento dado às imagens relativas ao corpo e à atividade física presentes nos livros de texto de Educação Física na etapa de Ensino Fundamental. A mostra está constituída por 997 imagens de nove livros de texto publicados por cinco editoras. Realizou-se uma análise descritiva das variáveis sexo, idade, raça e somatotipo que fazem referência ao corpo, e o variáveis tipo, âmbito, espaço e nível de prática referentes à atividade física. Os resultados mostram que se mantêm os estereótipos relativos ao corpo e à atividade física, enfatizando o corpo masculino, de raça branca, com um corpo delgado e cuja idade é a infância, praticando desportos e habilidades motrizes. No entanto, o âmbito e nível de prática de atividade física elitista desapareceu dos manuais, mostrando um primeiro passo para a diversificação de atividades físicas na escola.

Abstract: The aim of the present study is to determine the treatment given to the pictures of the body and physical activity in Physical Education's textbooks for Primary School. The sample consists of 997 images of nine textbooks published by five publishers. A descriptive analysis was performed on the variables gender, age, race, and somatotype that refer to the body, and type, scope, space, and level of practice referred to physical activity. Results show that stereotypes still remain regarding the body and physical activity, emphasizing the male, white, thin and youth body that practices sports and motor skills. However, the scope and level of elitist physical activity disappeared from manuals, which is a first step in diversifying school physical activities.
* Universidad de Valencia. Valencia, Espanha.

E-mail: irene.moyamata@gmail.com

** Universidad Católica de Valencia "San Vicente Mártir".. Valencia, Espanha.

E-mail: concepcion.ros@ucv.es

Recebido em: 09-06-2016 Aprovado em: 26-09-2016

(c) (1) (8) Licence 


\section{INTRODUCCIÓN}

En España, en la década de 1990 con la Ley Orgánica General del Sistema Educativo (LOGSE) (ESPAÑA, 1990) se incorporaron los materiales curriculares al contexto educativo, entendiéndose como "[...] instrumentos u objetos que se utilizan en el contexto escolar como mediadores del proceso de enseñanza-aprendizaje, que suponen la implicación del profesorado y el alumnado en este proceso" (MOLINA; DEVÍS; PEIRÓ, 2008, p.187).

Entre los materiales curriculares impresos encontramos el libro de texto, permitiendo innovar y favorecer una relación significativa entre las clases teóricas y las clases prácticas, siempre y cuando los docentes presenten una actitud crítica, abierta y activa en la utilización de estos recursos (DEVÍS; PEIRÓ, 2004).

Aunque la importancia del libro de texto en el área de Educación Física (EF) radica en ser un instrumento auxiliar, contribuye a la adquisición de conocimientos y participa en el proceso de transmisión de modelos de comportamiento social, normas, valores y, en algunos casos, de discriminación y exclusión social (BRUGEILLES; CROMER, 2009). Por tanto los libros de texto contienen concepciones ideológicas, políticas, éticas, antropológicas, psicológicas y culturales, a veces explícitas, a veces implícitas, que merecen ser analizadas (RAMíREZ, 2002). El texto escolar, según Garreta (1984), además de su contenido explícito, transmite parte de una cultura, describe un tipo de realidad social, unas formas de organizarse, unos valores, unas maneras de expresar las emociones, unas normas, unos modelos de vida, entre otros. Estos modelos culturales, si bien no son objeto de la asignatura estudiada, subyacen en todos los libros y van conformando de forma solapada, unos valores que, sin lugar a dudas, reflejan los del autor, los cuales de alguna manera son eco de valores compartidos en la sociedad. Se produce pues, un proceso de enculturación (PÉREZ; SÁNCHEZ; ROS, 2011), que mediante la transmisión de información tiene como finalidad, asegurar la integración y cohesión de los niños, niñas y los jóvenes en un grupo.

Es necesario realizar análisis que permitan identificar qué mensajes subliminales, qué sistema de valores subyacentes transmiten los libros de texto y verificar si presenta, ya sea en sus contenidos (BOTELHO, 2012), o imágenes, manifestaciones de estereotipos, prejuicios y discriminaciones relacionadas con la EF. Desde la perspectiva de las ciencias del deporte el estudio de imágenes tiene varios precedentes: referido a los libros de textos en secundaria, destacan diversos estudios (GONZÁLEZ, 2005; GONZÁLEZ-PALOMARES; REY-CAO, 2012, PARRA, 2002; TÁBOAS; REY, 2007, 2009, 2011, TÁBOAS-PAIS; REY-CAO, 2012a), mientras que en primaria destacan los estudios de Moya, Ros, Bastida y Menescardi (2013), MoyaMata, Ros, Menescardi (2014a) y Moya-Mata, Ros, Menescardi y Bastida (2014b). Todas estas investigaciones concluyen que las imágenes fijas del cuerpo, contenidas en los soportes estudiados, transmiten estereotipos propios de la sociedad actual.

Entre otros valores y estereotipos proclives de ser desentrañados de los textos escolares se encuentran los que tienen que ver con la religión, el sexo, condiciones socioeconómicas, origen geográfico, color de piel, etc. Uno de los tipos de discriminación más generalizada es la de género, siendo objeto de diversos estudios previos (GONZÁLEZ, 2005; GONZÁLEZ; TÁBOAS; REY, 2010; MOYA et al., 2013; MOYA-MATA et al., 2014a; PARRA, 2002; TÁBOAS; REY, 2007, 2011), en las que se muestra una predominancia de la imagen del hombre frente a la de la mujer. De igual modo ocurre con la raza, siendo la blanca la más representada (BOTELHO et al., 
2008; MOYA et al., 2013, MOYA-MATA et al., 2014; TÁBOAS; REY, 2011; TORRES, 2008). Otro estereotipo generalizado es el tipo de cuerpo representado siendo en su mayoría el somatotipo ectomorfo o cuerpo delgado el que impregna los materiales curriculares (MOYA-MATA et al., 2014b; TÁBOAS; REY, 2007, 2011); podemos observar, como la cultura del músculo reservada a los chicos y la cultura de la delgadez para las mujeres, arraigadas en el actual imaginario social, condicionan la realización de actividades físicas de hombres y mujeres (GONZÁLEZ et al., 2004). Asimismo, la franja etaria más representada es la niñez (MOYA-MATA et al., 2014; SÁNCHEZ; BÓDALO, 2000), invisibilizando a las personas de mayor edad (BLANCO, 2000; FANJUL, 2008; GARRETA; CAREAGA, 1987, REY-CAO; TÁBOAS-PAIS; CANALES, 2013) y con discapacidad (BOTELHO et al., 2008; TÁBOAS-PAIS; REY-CAO, 2012b, HARDIN; HARDIN, 2004). Este desequilibrio adquiere relevancia ya que, al igual que con los estereotipos sexistas o raciales, se da una relación entre esta creencia y la práctica de actividad física de las personas mayores o con discapacidad. La participación de los diferentes grupos de edad o colectivos en la actividad física estará influenciada por las creencias que se trasmiten sobre ellos y que se incrustan en el pensamiento de la sociedad (MOSCOSO; MOYANO, 2009).

Otros estudios se han analizado las imágenes las portadas de los videojuegos de género deportivo (RAMÍREZ, 2011), que confirma la reproducción de estereotipos corporales. López Villar (2011) y Fanjul (2008) reflejan la reproducción de estos estereotipos a través de las imágenes publicitarias relacionadas con el campo de la actividad física y el deporte. Asimismo, en algunas investigaciones se observa un carácter competitivo de la actividad física reflejado en los libros de texto de EF (TÁBOAS; REY, 2009, TÁBOAS-PAIS; REY-CAO, 2012a), así como el alto nivel en que aparece en contextos de competición o entrenamiento, conlleva una visión elitista y selectiva del deporte (BORES; DÍAZ, 1999; TÁBOAS; REY, 2009, TÁBOASPAIS; REY-CAO, 2012a), en contraposición con las clases de EF que se llevan a cabo en el ámbito de la enseñanza formal.

La preocupación sobre la transmisión estereotipada que pueden generar las imágenes de los libros de texto de Educación Física en la etapa de primaria son motivos más que suficientes para realizar esta investigación. Por todo ello, partiendo tanto de la necesidad de seguir estudiando las imágenes fijas del cuerpo en diferentes soportes, se planteó el siguiente objeto de investigación: determinar la presencia de estereotipos, corporales y referentes al tipo de actividad física, representados en las imágenes publicadas en los manuales de educación física en primaria.

\section{MÉTODO}

El estudio es de tipo empírico, descriptivo y comparativo (HEINEMANN, 2003) y frecuencial (PIÑUEL, 2002), utilizando el análisis de contenido como técnica central (NEUENDORF, 2011). Las imágenes que aparecen en los libros de texto de EF (fotografías y viñetas dibujadas) son las unidades de muestreo.

\subsection{Muestra}

La muestra está constituida por 997 imágenes, recogidas en nueve libros de texto publicados por cinco editoriales diferentes (Tabla 1). Los criterios establecidos para la 
selección de los libros de las editoriales son los siguientes: (1) pertenecer al área de EF; (2) estar destinados al alumnado del tercer ciclo de la Educación Primaria, ya que en este ciclo el alumnado se encuentra en la etapa de Operaciones Formales, según la teoría de Piaget, donde el niño se descentra de sí mismo, distingue a otros grupos y razas, y así como el desarrollo de conceptos morales (LÓPEZ et al., 1988); (3) publicados en lengua castellana; (4) adaptados al Sistema Educativo Español y, (5) editados a partir de la Ley Orgánica de Educación (LOE), (ESPAÑA, 2006a), siendo los más actuales de los publicados por cada editorial (en el caso de que haya más de una edición). La muestra se agrupó en función de las editoriales.

Tabla 1 - Descripción de la muestra por editorial y curso.

\begin{tabular}{llccc}
\hline Editorial & Curso & Año Publicación & Imágenes & Imágenes Ciclo \\
\hline \multirow{2}{*}{ Anaya } & Quinto curso & 2009 & 150 & 305 \\
& Sexto curso & 2009 & 155 & 215 \\
\multirow{2}{*}{ Bruño } & Quinto curso & 2012 & 123 & \multirow{2}{*}{123} \\
& Sexto curso & 2012 & 92 & \multirow{2}{*}{178} \\
\multirow{2}{*}{ Inde } & Quinto curso & 2008 & 46 & 17 \\
\hline \multirow{2}{*}{ Paidotribo } & Sexto curso & 2008 & 61 & 176 \\
& Quinto curso & 2008 & 117 & \\
\hline Serbal & Sexto curso & 2008 & 176 &
\end{tabular}

\subsection{Instrumento}

El instrumento de análisis utilizado para clasificar las imágenes de los libros de textos de EF es una planilla diseñada ad hoc para la etapa de Educación Primaria, utilizada en investigaciones previas (MOYA et al., 2013; MOYA-MATA et al., 2014a, 2014b) (Tabla 2).

Tabla 2 - Variables referidas al cuerpo y a la actividad física.

\begin{tabular}{|c|c|c|c|}
\hline Var & bles & Definición & Indicadores \\
\hline \multirow{4}{*}{$\begin{array}{l}\text { Referidas } \\
\text { al cuerpo }\end{array}$} & Sexo & $\begin{array}{l}\text { Condición bilógica y natural que diferencia entre } \\
\text { hombres y mujeres; y distribución. }\end{array}$ & $\begin{array}{l}\text { Masculino } \\
\text { Femenino } \\
\text { Mixto } \\
\text { No se distingue }\end{array}$ \\
\hline & Raza & $\begin{array}{c}\text { Grupo en que se subdivide la raza humana } \\
\text { biológicamente, manifestado por el color de la piel, los } \\
\text { ojos y/o ancho de la nariz }\end{array}$ & $\begin{array}{c}\text { Blanca } \\
\text { Negra } \\
\text { Otras } \\
\text { No se distingue }\end{array}$ \\
\hline & Somatotipo & Forma, estructura o morfología corporal de un sujeto. & $\begin{array}{c}\text { Mesomorfo } \\
\text { Endomorfo } \\
\text { Ectomorfo } \\
\text { Otros } \\
\text { No se distingue }\end{array}$ \\
\hline & Edad & $\begin{array}{l}\text { Tiempo vivido por un sujeto, determinado por su } \\
\text { apariencia externa. }\end{array}$ & $\begin{array}{c}\text { Niño } \\
\text { Joven } \\
\text { Otros } \\
\text { No se distingue }\end{array}$ \\
\hline
\end{tabular}




\begin{tabular}{|c|c|c|c|}
\hline \multirow{4}{*}{$\begin{array}{l}\text { Referidas a } \\
\text { la actividad } \\
\quad \text { física }\end{array}$} & $\begin{array}{l}\text { Bloque de } \\
\text { contenido }\end{array}$ & $\begin{array}{l}\text { Tipo de actividad física correspondiente con cada } \\
\text { uno de los bloques del curriculum definidos en el RD } \\
1513 / 2006 \text {. }\end{array}$ & $\begin{array}{l}\text { Cuerpo: imagen y percepción } \\
\text { Habilidades motrices } \\
\text { Expresivas-artísticas } \\
\text { Actividad. física y salud } \\
\text { Juegos y deportes } \\
\text { Otros }\end{array}$ \\
\hline & Ámbito & $\begin{array}{l}\text { Contexto configurado por las características propias de } \\
\text { la práctica. }\end{array}$ & $\begin{array}{l}\text { Competitivo } \\
\text { Educativo } \\
\text { Recreacional } \\
\text { Utilitario } \\
\text { Otros } \\
\text { No se distingue }\end{array}$ \\
\hline & Espacio & Entorno o ambiente físico que rodea a la actividad. & $\begin{array}{c}\text { Exterior } \\
\text { Medio natural } \\
\text { Interior } \\
\text { No se distingue }\end{array}$ \\
\hline & Nivel & $\begin{array}{c}\text { Grado de seriedad, entrega, dedicación y/o } \\
\text { profesionalidad. }\end{array}$ & $\begin{array}{c}\text { Elite } \\
\text { No élite } \\
\text { No se distingue }\end{array}$ \\
\hline
\end{tabular}

Fuente: datos de las autoras.

Para la elaboración de este instrumento de análisis se llevaron a cabo seis fases, al igual que en investigaciones anteriores (MOYA et al., 2013), como detallamos a continuación: 1. Prueba piloto de pertinencia del instrumento; 2. Adaptación del instrumento a la etapa de Primaria; 3. Segunda prueba piloto; 4. Panel de expertos, 5. Reelaboración en base a la opinión de los expertos, y 6 . Triangulación con dos observadores. La consulta a expertos se hizo siguiendo la línea de adecuación del instrumento al objeto de estudio; los criterios de exhaustividad y mutua exclusividad; y la minimización de la subjetividad del observador, como criterios de cientificidad.

\subsection{Análisis de los datos}

Las imágenes fueron analizadas por dos observadores, con experiencia en el ámbito del análisis de las imágenes impresas en libros de texto, ambos licenciados en Ciencias de la Actividad Física y el Deporte. Siguiendo la línea de investigaciones anteriores (MOYA-MATA; RUIZ-SANCHÍS; ROS, 2016) se realizó un proceso de entrenamiento de los observadores, previo al análisis de las imágenes. En esta fase se determinó la fiabilidad del instrumento mediante el análisis del $10 \%$ de la muestra seleccionado mediante un muestreo por conveniencia (100 imágenes) por los dos codificadores obteniéndose un acuerdo casi excelente (Kappa de Cohen $=0,83$ ).

Se utilizaron tablas de contingencia para comparar las frecuencias observadas y los porcentajes. Se utilizó el estadístico chi-cuadrado $\left(\chi^{2}\right)$ junto con la V de Cramer ( $V$ para establecer relaciones entre las variables así como la intensidad de éstas. Asimismo, se utilizó el análisis de los residuos tipificados corregidos (RTC) para interpretar las tablas de contingencia y poder compararlos, ya que de otro modo los valores marginales, el tamaño muestral y el número de casos en los que se fundamentaba cada residuo impedirían dicha comparación (TABOAS; REY, 2012c). 


\section{RESULTADOS}

Los resultados obtenidos muestran que el cuerpo masculino es el más representado $(39,52 \%)$, seguido del cuerpo femenino $(28,49 \%)$ y de las imágenes con ambos sexos (27,78\%). Esta es la tendencia general salvo en la editorial Paidotribo que tiene un $42,70 \%$ de imágenes, tanto de "hombres" como de "mujeres". Asimismo, dentro del sexo encontramos que mientras Inde representa en gran medida los hombres (78\%), Anaya lo hace en un porcentaje inferior al resto $(21 \%)$, optando esta última por la representación del grupo mixto (11\%) en comparación con Inde y Paidotribo ( $5 \%$ y $6 \%$, respectivamente) $\left(\chi^{2}=236,883 ; p\right.$ $\langle 0,01 ; V=0,28)$. Respecto a la representación de la raza encontramos en primer lugar la raza "blanca" $(46,54 \%)$, frente a "otras" razas, $(27,18 \%)$ o la raza "negra" $(6,62 \%)$. La editorial Serbal destaca por su gran representación de la raza blanca $(81 \%)$ mientras que lo contrario sucede con Inde (10\%), asimismo, Anaya destaca por tener un $55,74 \%$ de imágenes de sujetos de "otras" razas $\left(\chi^{2}=215,323 ; p<0,01 ; V=0,33\right)$. En cuanto al somatotipo predomina el "ectomorfo" (48,75\%), seguido del "endomorfo" (24,97\%) y el "mesomorfo" $(14,04 \%)$; siendo la editorial Anaya la que destaca por sujetos "endomorfos" (79\%), y la editorial Serbal por sujetos "mesomorfo" $(50,57 \%)\left(\chi^{2}=709,143 ; p<0,01 ; V=0,49\right)$. Asimismo señalar que la mayor parte de la muestra está representada por niños y niñas $(83,85 \%)$, seguido por jóvenes $(4,51)$ y otros $(2,81 \%)$, destacándose la editorial Paidotribo en la cual hay un gran porcentaje de cuerpos donde no se puede reconocer la edad (36\%), mientras que el porcentaje de cuerpos jóvenes es significativamente menor que el de las otras editoriales $(61 \%)\left(\chi^{2}=215,323 ; p<0,01 ; V=0,33\right)$.

Tabla 3 - Recuento de las variables de sexo, raza, somatotipo y edad (estereotipos corporales).

\begin{tabular}{|c|c|c|c|c|c|c|c|c|}
\hline & & & \multicolumn{5}{|c|}{ EDITORIAL } & \multirow[b]{2}{*}{$\begin{array}{c}\text { Total } \\
(\mathrm{n}=997)\end{array}$} \\
\hline & & & $\begin{array}{c}\text { Inde } \\
(n=123)\end{array}$ & $\begin{array}{c}\text { Paidotribo } \\
(\mathrm{n}=178)\end{array}$ & $\begin{array}{c}\text { Bruño } \\
(n=215)\end{array}$ & $\begin{array}{c}\text { Anaya } \\
(n=305)\end{array}$ & $\begin{array}{c}\text { Serbal } \\
(n=176)\end{array}$ & \\
\hline \multirow{12}{*}{ SEXO } & \multirow{3}{*}{ Hombre } & Frec. & 97 & 76 & 88 & 65 & 68 & 394 \\
\hline & & $\%$ & $78,9 \%$ & $42,7 \%$ & $40,9 \%$ & $21,3 \%$ & $38,6 \%$ & $39,5 \%$ \\
\hline & & RTC & 9,5 & 1,0 & 0,5 & $-7,8$ & $-0,3$ & \\
\hline & \multirow{3}{*}{ Mujer } & Frec. & 13 & 76 & 74 & 69 & 52 & 284 \\
\hline & & $\%$ & $10,6 \%$ & $42,7 \%$ & $34,4 \%$ & $22,6 \%$ & $29,5 \%$ & $28,5 \%$ \\
\hline & & RTC & $-4,7$ & 4,6 & 2,2 & $-2,7$ & 0,3 & \\
\hline & \multirow{3}{*}{ Mixto } & Frec. & 6 & 12 & 46 & 157 & 55 & 276 \\
\hline & & $\%$ & $4,9 \%$ & $6,7 \%$ & $21,4 \%$ & $51,5 \%$ & $31,3 \%$ & $27,7 \%$ \\
\hline & & RTC & $-6,0$ & $-6,9$ & $-2,3$ & 11,1 & 1,2 & \\
\hline & \multirow{3}{*}{$\mathrm{N} / \mathrm{S}$} & Frec. & 7 & 14 & 7 & 14 & 1 & 43 \\
\hline & & $\%$ & $5,7 \%$ & $7,9 \%$ & $3,3 \%$ & $4,6 \%$ & $0,6 \%$ & $4,3 \%$ \\
\hline & & & 0,8 & 2,6 & $-0,9$ & 0,3 & $-2,7$ & \\
\hline \multirow{12}{*}{ RAZA } & \multirow{3}{*}{ Blanca } & Frec. & 13 & 102 & 96 & 110 & 143 & 464 \\
\hline & & $\%$ & $10,6 \%$ & $57,3 \%$ & $44,7 \%$ & $36,1 \%$ & $81,3 \%$ & $46,5 \%$ \\
\hline & & RTC & $-8,5$ & 3,2 & $-0,6$ & $-4,4$ & 10,2 & \\
\hline & \multirow{3}{*}{ Negra } & Frec. & 3 & 2 & 31 & 14 & 16 & 66 \\
\hline & & $\%$ & $2,4 \%$ & $1,1 \%$ & $14,4 \%$ & $4,6 \%$ & $9,1 \%$ & $6,6 \%$ \\
\hline & & RTC & $-2,0$ & $-3,3$ & 5,2 & $-1,7$ & 1,5 & \\
\hline & \multirow{3}{*}{ Otras } & Frec. & 6 & 0 & 82 & 170 & 13 & 271 \\
\hline & & $\%$ & $4,9 \%$ & $0,0 \%$ & $38,1 \%$ & $55,7 \%$ & $7,4 \%$ & $27,2 \%$ \\
\hline & & RTC & $-5,9$ & $-9,0$ & 4,1 & 13,5 & $-6,5$ & \\
\hline & \multirow{3}{*}{$\mathrm{N} / \mathrm{S}$} & Frec. & 101 & 74 & 6 & 11 & 4 & 196 \\
\hline & & $\%$ & $82,1 \%$ & $41,6 \%$ & $2,8 \%$ & $3,6 \%$ & $2,3 \%$ & $19,7 \%$ \\
\hline & & & 18,6 & 8,1 & $-7,0$ & $-8,5$ & $-6,4$ & \\
\hline & \multicolumn{8}{|c|}{ Continúa en la página siguiente. } \\
\hline
\end{tabular}




\begin{tabular}{|c|c|c|c|c|c|c|c|c|}
\hline \multirow{15}{*}{$\begin{array}{c}\text { SOMA } \\
\text { TOTIPO }\end{array}$} & \multirow{3}{*}{ Mesomorfo } & Frec. & 13 & 24 & 11 & 3 & 89 & 140 \\
\hline & & $\%$ & $10,6 \%$ & $13,5 \%$ & $5,1 \%$ & $1,0 \%$ & $50,6 \%$ & $14,0 \%$ \\
\hline & & RTC & $-1,2$ & $-0,2$ & $-4,3$ & $-7,9$ & 15,4 & \\
\hline & \multirow{3}{*}{ Endomorfo } & Frec. & 0 & 0 & 0 & 241 & 8 & 249 \\
\hline & & $\%$ & $0,0 \%$ & $0,0 \%$ & $0,0 \%$ & $79,0 \%$ & $4,5 \%$ & $25,0 \%$ \\
\hline & & RTC & $-6,8$ & $-8,5$ & $-9,6$ & 26,2 & $-6,9$ & \\
\hline & \multirow{3}{*}{ Ectomorfo } & Frec. & 102 & 105 & 203 & 23 & 54 & 487 \\
\hline & & $\%$ & $82,9 \%$ & $59,0 \%$ & $94,4 \%$ & $7,5 \%$ & $30,7 \%$ & $48,8 \%$ \\
\hline & & RTC & 8,1 & 3,0 & 15,1 & $-17,3$ & $-5,3$ & \\
\hline & \multirow{3}{*}{ Varios } & Frec. & 1 & 0 & 0 & 17 & 14 & 32 \\
\hline & & $\%$ & $0,8 \%$ & $0,0 \%$ & $0,0 \%$ & $5,6 \%$ & $8,0 \%$ & $3,2 \%$ \\
\hline & & RTC & $-1,6$ & $-2,7$ & $-3,0$ & 2,8 & 3,9 & \\
\hline & \multirow{3}{*}{$\mathrm{N} / \mathrm{S}$} & Frec. & 7 & 49 & 1 & 21 & 11 & 89 \\
\hline & & $\%$ & $5,7 \%$ & $27,5 \%$ & $0,5 \%$ & $6,9 \%$ & $6,3 \%$ & $8,9 \%$ \\
\hline & & & $-1,3$ & 9,6 & $-4,9$ & $-1,5$ & $-1,4$ & \\
\hline \multirow{9}{*}{ EDAD } & \multirow{3}{*}{ Joven } & Frec. & 118 & 109 & 206 & 279 & 169 & 881 \\
\hline & & $\%$ & $95,9 \%$ & $61,2 \%$ & $95,8 \%$ & $91,5 \%$ & $96,0 \%$ & $88,4 \%$ \\
\hline & & RTC & 2,8 & $-12,5$ & 3,8 & 2,0 & 3,5 & \\
\hline & \multirow{3}{*}{ Otros } & Frec. & 1 & 4 & 3 & 14 & 6 & 28 \\
\hline & & $\%$ & $0,8 \%$ & $2,2 \%$ & $1,4 \%$ & $4,6 \%$ & $3,4 \%$ & $2,8 \%$ \\
\hline & & RTC & $-1,4$ & $-0,5$ & $-1,4$ & 2,3 & 0,5 & \\
\hline & \multirow{3}{*}{$\mathrm{N} / \mathrm{s}$} & Frec. & 4 & 65 & 6 & 12 & 1 & 88 \\
\hline & & $\%$ & $3,3 \%$ & $36,5 \%$ & $2,8 \%$ & $3,9 \%$ & $0,6 \%$ & $8,8 \%$ \\
\hline & & & $-2,3$ & 14,4 & $-3,5$ & $-3,6$ & $-4,3$ & \\
\hline
\end{tabular}

Fuente: datos de las autoras.

La Tabla 4 muestra las variables de ámbito, espacio y nivel de práctica de actividad física, la cual va a determinar la presencia o no de estereotipos relativos al tipo de actividad física practicada. Las actividades predominantes son las "habilidades motrices" (34,30\%) y "juegos y deportes" (34\%); y en menor medida las actividades de "expresión artística" (8,63\%) y "actividad física y salud" (6,02\%). Se puede observar la mayor representación de los bloques de imagen y percepción, habilidades motrices y expresión artística en la editorial Anaya (8\%, $43 \%$ y $13 \%$, respectivamente) en detrimento de juegos y deportes $(21 \%)$ donde es una de las editoriales que menos los representa, siendo Serbal la que más $(65 \%)\left(\chi^{2}=391,974 ; p<0,01\right.$; $V=0,31)$. Respecto al ámbito, la mayor parte de la muestra "no se distingue" $(81,85 \%)$, seguido del "competitivo" (6,42\%). En este sentido, la editorial Bruño muestra muchas imágenes donde no se puede distinguir el ámbito (93\%) mientras que Serbal es la que menos (65\%), optando por los ámbitos competitivo (15\%) y recreacional $(11 \%)\left(\chi^{2}=157,321 ; p<0,01 ; V=0,19\right)$ Asimismo el espacio tampoco suele distinguirse $(88,06 \%)$. Nuevamente destaca la editorial Serbal por su amplio porcentaje de imágenes en el medio natural (8\%) en comparación con el resto de editoriales $\left(\chi^{2}=64,467 ; p<0,01 ; V=0,15\right)$. Y en cuanto al nivel predomina la "no élite" (78,64\%) frente a la "élite" (4,21\%); siendo las editoriales Bruño y Anaya las que más representan la élite ( $97 \%$ y $100 \%$, respectivamente) mientras que las que menos lo hacen son Paidotribo y Serbal ( $49 \%$ y $56 \%$, respectivamente), las cuales prefieren representar imágenes donde no se distinga el nivel (44\% y $36 \%$, respectivamente).

En la categoría raza $\left(\chi^{2}=27,867 ; p<0,01 ; V=0,12\right)$ (Gráfico 1$)$, la raza "blanca" y "otras" se asocian más a actividades de "habilidades motrices" y "juegos y deportes", mientras que en las actividades "artísticas" y de "actividad física y salud" predominan "otras" razas. En cuanto al nivel, la raza "negra" se relaciona con el ámbito "competitivo" (gráfico 2), mientras que 
la raza "blanca" se relaciona con los ámbitos "competitivo", "utilitario" y "recreacional". "Otras" razas tienen una presencia similar en todos los ámbitos $\left(\chi^{2}=30,152 ; p<0,01 ; V=0,12\right)$. La asociación entre las variables "raza" y "élite" se muestra en la tabla 5 , siendo dependientes $\left(\chi^{2}\right.$ $=76,465 ; p<0,01 ; V=0,20)$, estando asociada, en mayor medida, la élite a la raza blanca.

Tabla 4 - Recuento de las variables de bloque de contenido, ámbito, espacio y nivel de práctica de actividad física.

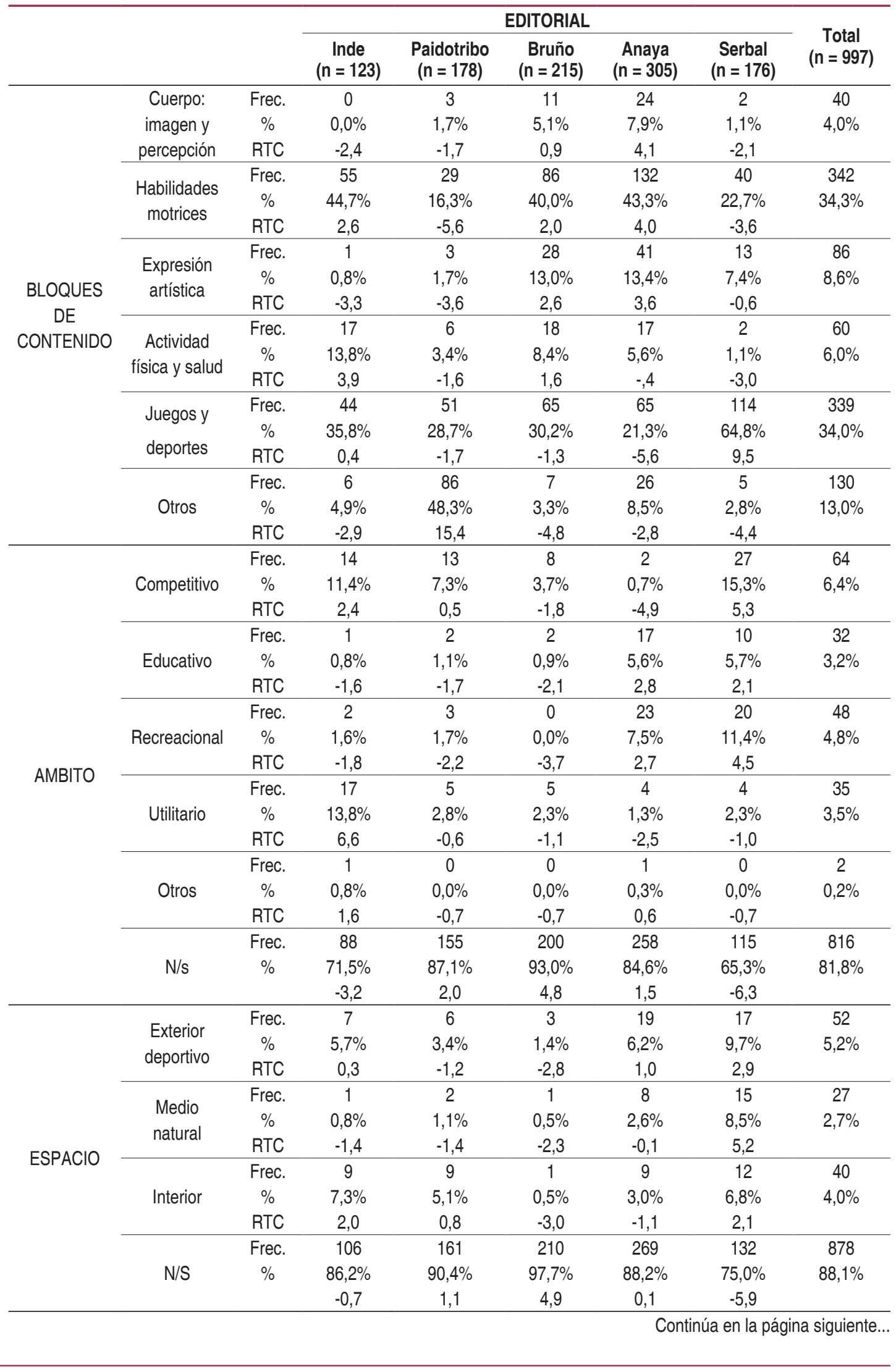


Tabla 4 Continuación...

\begin{tabular}{|c|c|c|c|c|c|c|c|c|}
\hline & & Frec. & 12 & 12 & 5 & 0 & 13 & 42 \\
\hline & Elite & $\%$ & $9,8 \%$ & $6,7 \%$ & $2,3 \%$ & $0,0 \%$ & $7,4 \%$ & $4,2 \%$ \\
\hline & & RTC & 3,3 & 1,9 & $-1,6$ & $-4,4$ & 2,3 & \\
\hline & & Frec. & 84 & 87 & 209 & 305 & 99 & 784 \\
\hline \multirow[t]{5}{*}{ ELITE } & No élite & $\%$ & $68,3 \%$ & $48,9 \%$ & $97,2 \%$ & $100,0 \%$ & $56,3 \%$ & $78,6 \%$ \\
\hline & & RTC & $-3,2$ & $-10,6$ & 7,5 & 11,0 & $-7,9$ & \\
\hline & & Frec. & 27 & 79 & 1 & 0 & 64 & 171 \\
\hline & $\mathrm{N} / \mathrm{S}$ & $\%$ & $22,0 \%$ & $44,4 \%$ & $0,5 \%$ & $0,0 \%$ & $36,4 \%$ & $17,2 \%$ \\
\hline & & & 1,5 & 10,6 & $-7,3$ & $-9,5$ & 7,5 & \\
\hline
\end{tabular}

Fuente: datos de las autoras.

Gráfico 1 - Asociación de las variables actividad física y raza de los sujetos.

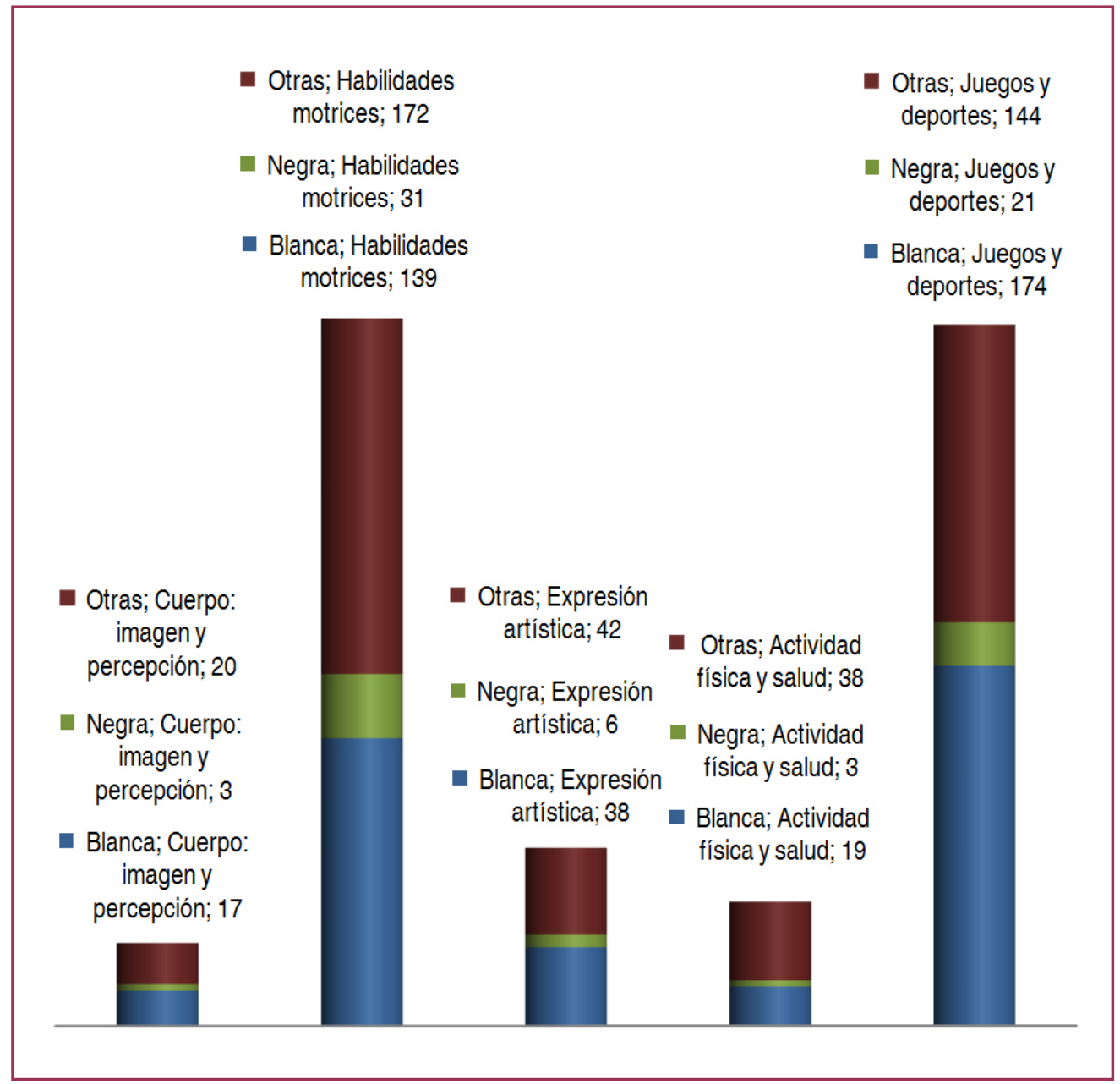

Fuente: datos de las autoras.

Tabla 5 - Tabla de contingencia nivel de actividad física y raza de los sujetos.

\begin{tabular}{ccccc}
\hline & Blanca & Negra & Otras & Total \\
\hline Elite & 31 & 6 & 5 & 42 \\
No élite & 313 & 50 & 421 & 784 \\
N/S & 120 & 10 & 41 & 171 \\
\hline Total & 464 & 66 & 467 & 997 \\
\hline
\end{tabular}

Fuente: datos de las autoras. 
Los hombres se representa realizando más actividades de "habilidades motrices" y "juegos y deportes", las mujeres destacan por realizar actividades de "otros" contenidos y del "cuerpo: imagen y percepción", mientras que las otras agrupaciones destacan por su gran porcentaje de actividades de expresión artística $\left(\chi^{2}=88,142 ; p<0,01 ; V=0,21\right)$ (Gráfico 2).

Gráfico 2 - Asociación de las variables de actividad física y sexo de los sujetos.

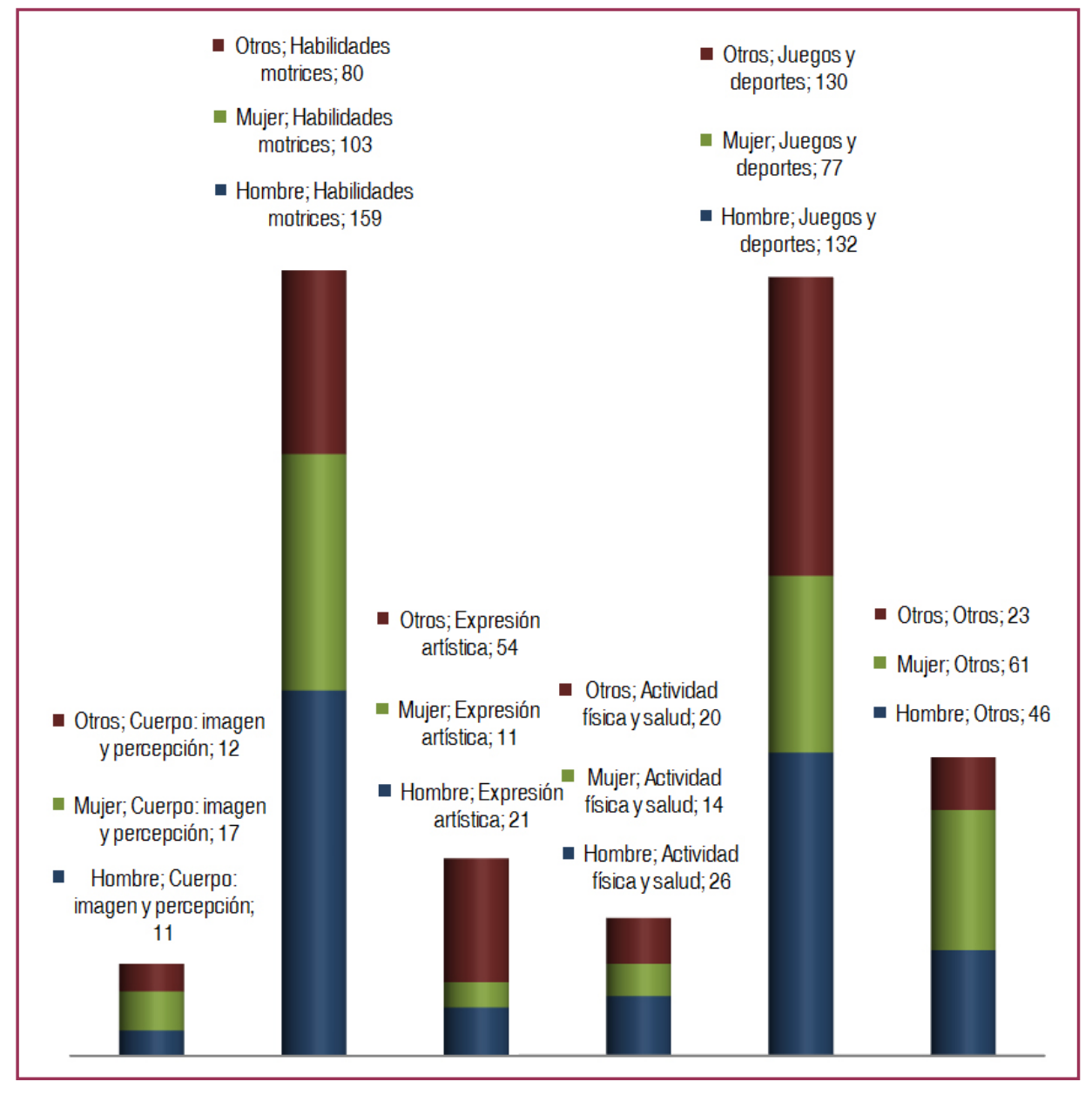

Fuente: datos de las autoras.

Respecto al ámbito, los hombres están más representados en los ámbitos "competitivo" y "utilitario", mientras que las mujeres están más representadas en el ámbito "recreacional" y "competitivo"; en este segundo caso, supeditada al hombre. Las otras agrupaciones se asocian a los ámbitos "educativo" y "recreacional" ( $\left.\chi^{2}=98,310 ; p<0,01 ; V=0,22\right)$. En cuanto al nivel, se asocia el sexo "masculino" a la "élite" frente a las mujeres y las otras agrupaciones $\left(\chi^{2}=\right.$ 40,$594 ; p<0,01 ; V=0,14$ ) (tabla 6).

Tabla 6 - Tabla de contingencia nivel de actividad física y sexo de los sujetos.

\begin{tabular}{ccccc}
\hline & Hombre & Mujer & Otros & Total \\
\hline Elite & 30 & 8 & 4 & 42 \\
No élite & 285 & 215 & 284 & 784 \\
N/S & 80 & 60 & 31 & 171 \\
\hline Total & 395 & 283 & 319 & 997 \\
\hline
\end{tabular}




\section{DISCUSIÓN}

El objetivo de esta investigación fue determinar la existencia de estereotipos corporales y referentes al tipo de actividad física representada en las imágenes publicadas en manuales de educación física en primaria. Los resultados muestran que el cuerpo masculino es el más representado. Esto coincide con estudios previos que muestran la predominancia del sexo masculino frente al femenino (BLANCO, 2000; GONZÁLEZ, 2005; GONZÁLEZ; REY; TÁBOAS, 2010; MOYA et al., 2013; MOYA-MATA et al., 2014a; PARRA, 2002; RAMÍREZ, 2002, 2011; TÁBOAS; REY, 2007, 2009, 2011). Por otro lado los hombres están relacionados con actividades de condición física y juegos y deportes, así como al ámbito competitivo y la élite (MOYA et al., 2013; TÁBOAS; REY, 2011; TIRADO, 2006; SCHARAGRODSKY, 2003).

Respecto a la variable raza y en concordancia con estudios previos (BOTELHO et al., 2008; LÓPEZ, 2011; RAMÍREZ, 2002, 2011; TÁBOAS; REY, 2007, 2011), se observa una mayor representación de sujetos de raza blanca, frente a otras razas; incluso diversos estudios denuncian la no existencia de personas de raza diferente a la blanca (CALVO, 1989; LLUCH, 2011; MORENO, 1986; SERRA; ALEGRET, 1997; TORRES, 2008). Sin embargo, es reseñable que la segunda agrupación más representada sea "otras" razas, donde se agrupan a los sujetos de raza latinoamericana, asiática, indígena, etc., mostrando la diversidad y multiculturalidad presente en la escuela. Esta multiculturalidad la muestran los estudios del Instituto Nacional de Estadística (INE), siendo la población española actual de 10 a 14 años de 277.319 individuos, de los cuales el 20.257 son de nacionalidad española, mientras que el resto lo forman, por orden, niños y niñas con nacionalidad de los países americanos (113.880), países de la Unión Europea (110.469), países africanos (40.125), países asiáticos (12.754), países europeos no comunitarios (9.718) y países de Oceanía (96) (INSTITUTO..., 2015).

El tipo de práctica realizada en función de la raza, según los resultados obtenidos muestran que la raza blanca se asocia más a actividades de condición física y habilidades, así como las actividades utilitarias, higiénicas y de salud, mientras que la raza negra se asocia a la condición física y a los juegos y deportes, principalmente. Hay una presencia destacable de otras razas en las actividades artísticas. En cuanto al nivel, la raza negra se relaciona con el ámbito competitivo, mientras que la raza blanca se relaciona con los ámbitos competitivo y el nivel de élite, utilitario y recreacional, y las otras razas lo hacen con los ámbitos utilitario, recreacional y educativo. Esto es contrario a los resultados mostrados por Táboas y Rey $(2009,2011)$ que muestran que los sujetos de raza blanca se vinculan mayoritariamente a las actividades físicas no deportivas, mientras que las personas de otras razas reciben una mayor atención en el deporte federado, ámbito competitivo y élite, mientras que su presencia en el ámbito formal educativo es inexistente. Esta diferencia en los resultados, puede deberse al análisis de las fotografías que realizan estos autores en su investigación, donde la gran mayoría se enmarcan dentro de la élite.

En cuanto al somatotipo, los sujetos representados en los manuales de educación física destacan por tener un cuerpo ectomorfo (delgado), tanto para hombres como para mujeres, lo cual difiere de los estudios en publicidad (FANJUL, 2008), videojuegos (RAMÍREZ, 2011) y en los libros de texto (TÁBOAS; REY, 2007, 2010, 2011) que señalan que el modelo corporal predominantemente masculino se corresponde con un somatotipo mesomorfo, mientras que el predominante femenino es el ectomorfo. La representación de los cuerpos cobra 
especial relevancia cuando las imágenes corporales idealizadas desencadenan en trastornos alimentarios o distorsiones somáticas las poblaciones vulnerables, como pueden ser la niñez y la adolescencia (FANJUL, 2008). En este sentido, la editorial Anaya destaca por ser la única con un porcentaje elevado de sujetos representados de tipo endomorfo, rompiendo con los estereotipos corporales de la delgadez presentes en otras editoriales.

La franja etaria más representada en las imágenes es el cuerpo joven, lo cual coincide con investigaciones previas (BLANCO, 2000; GARRETA; CAREAGA, 1987; FANJUL, 2008; MOYA-MATA et al., 2014b; SÁNCHEZ; BÓDALO, 2000; TÁBOAS; REY, 2011) que muestran la mayor presencia del cuerpo joven frente al resto de franjas etarias. Los estereotipos corporales de la sociedad actual, tales como vitalidad, seducción, juventud, etc. (LE BRETON, 1995) quedan alejados de la percepción que se tiene de las personas mayores (deterioro, fragilidad, impotencia, fealdad, etc.) (BARRET; CANTWELL, 2007), dejando poco espacio a la diversidad.

En relación a las actividades físicas más representadas en los manuales, coincidimos con investigaciones previas (GONZÁLEZ, 2005; MOYA-MATA et al., 2014a; TÁBOAS; REY, 2009, 2011) que muestran la desigualdad de contenidos representados, favoreciendo los contenidos de condición física y juegos y deportes. La existencia de estos contenidos prioritarios sobre otros secundarios como la expresión corporal o las actividades físicas en la naturaleza contradicen el Real Decreto 1513/2006 (ESPAÑA, 2006b) que establece el currículo de Primaria, y en donde se señala que a lo largo de la etapa se debe promover y facilitar al alumno, un número variado de actividades corporales y deportivas; que favorecerá una educación integral del alumnado.

Si nos referimos al ámbito y espacio de práctica, destacan ambos por ser no distinguidos en la mayoría de las imágenes, ya que al predominar el dibujo frente a la fotografia, suele aparecer en fondo blanco. Si eliminamos el ítem "no se distingue", encontramos que los ámbitos más representados son, por orden descendiente, el competitivo, el utilitario, el recreacional y finalmente, el educativo. Esto coincide con las investigaciones previas que muestran el ámbito competitivo como el más representado y el educativo el menos representado (TÁBOAS; REY, $2009,2011)$. Asimismo, los espacios más representados son el exterior, seguido del interior y el medio natural. Estos datos contrastan con los valores postmodernistas que han impulsado nuevas formas de practicar y vivir el deporte (p.ej. las actividades en la naturaleza), tal como señala el estudio de García Ferrando (2006), ya que el espacio menos representado es el medio natural. Asimismo, coincide con Táboas y Rey (2009), en que los espacios más representados son los de tipo deportivo.

El nivel de práctica deportiva representada en los libros de texto, se corresponde con imágenes de no élite, lo cual es contrario a investigaciones previas que muestran una educación física elitista (TÁBOAS; REY, 2009, 2011). Sin embargo, no se han analizado casi fotografías en los manuales, de las cuales podríamos aventurarnos a decir que en su mayoría se relacionan con la élite y la competición deportiva, debido a la aparición de deportistas famosos.

Entre las limitaciones de la investigación cabría destacar que algunas de las relaciones encontradas entre las diversas variables muestran una asociación leve $(V<0,2)$ o moderada ( $V$ $<0,4$ ) (REA; PARKER, 2014); por lo que en dichas asociaciones, éstas deben ser consideradas como una tendencia, y por tanto, dichos resultados deben tomarse en consideración con cautela. Asimismo, y como futuras líneas de investigación, se pretende ampliar el análisis de los libros de texto de Educación Física a toda la etapa de Educación Primaria. Pese a las limitaciones 
comentadas, esta herramienta de análisis permite clasificar las imágenes presentes en los manuales de cualquier etapa, con vistas a una enseñanza crítica y reflexiva que se preocupe por analizar la información de los libros de texto con los que enseñan. Todo ello, sin perder de vista el objetivo de la enseñanza que es la educación integral del alumno, dentro de una sociedad multicultural y sin discriminación.

\section{CONCLUSIONES}

Las conclusiones establecidas tras esta investigación son las siguientes:

- Las editoriales que publican los libros de texto de EF en el tercer ciclo de EP mantienen los estereotipos relativos al cuerpo, mostrando un mayor número de imágenes de individuos masculinos, de raza blanca, con un somatotipo ectomorfo y cuya edad se corresponde con la niñez, frente al resto de categorías analizadas.

- Las editoriales mantienen los estereotipos relativos a la actividad física, representado en mayor medida los juegos, los deportes y la condición física, dentro de los bloques de contenido: "Juegos y deportes" y "Habilidades motrices", frente al resto de los bloques de contenido establecidos en el currículo.

- Los estereotipos relativos al ámbito y nivel de práctica de actividad física representan principalmente imágenes en contextos diversos no elitistas, mostrando un primer paso para la diversificación de actividades físicas dentro de la escuela, alejadas de los estereotipos relativos a la actividad física y deportiva de élite.

\section{REFERENCIAS}

BARRET, Anne E.; CANTWELL, Laura E. Drawing on stereotypes: Using undergraduates' sketches of elders as a teaching tool. Educational Gerontology, v. 33, n. 4, p. 327-348, 2007.

BLANCO, Nieves. El sexismo en los materiales educativos de la E.S.O. Sevilla: Instituto Andaluz de la Mujer y Consejería de la Presidencia, 2000. (Serie Estudios, n. 13).

BORES, Nicolás; DÍAZ, Benito. De la anunciada e inevitable deportivización del currículum real de la Educación física. In: CONGRESO NACIONAL DE EDUCACIÓN FÍSICA, 17. 1999. Anales....Málaga: IAD, 1999. p. 172-189.

BOTELHO, Rafael G. Libros infantiles con temática relacionada con la Educación Física y el Deporte en Brasil: estudio de sus características. Bilbios: revista de Bibliotecología y Ciencias de la Información, n. 49, p. 44-53, 2012.

BOTELHO-GOMES, Paula; SILVA, Paula; QUEIRÓS, Telma; CAETANO, Silvia. Manuais de Educação Física: em rota de colisão com género, diversidade e cidadania. In: HENRIQUES, Fernanda. (ed.) Género, Diversidade e Cidadania. Lisboa: Colibri, 2008. p. 89-101.

BRUGEILLES, Carole; CROMER, Sylvie. Promoting gender equality through textbooks. A methodological guide. Paris: United Nations Educational, Scientific and Cultural Organization, 2009.

CALVO, Tomás. Los racistas son los otros: gitanos, minorías y derechos humanos en los textos escolares. Madrid: Editorial Popular, 1989. 
DEVÍS, José; PEIRÓ, Carmen. Los materiales curriculares en la Educación Física. In: FRAILE, Antonio (ed.). Didáctica de la educación física: una perspectiva crítica y transversal. Madrid: Biblioteca Nueva, 2004. p. 63-94

FANJUL, Carlos. Estereotipos publicitarios: el modelo fitness como factor de influencia social en la vigorexia masculina. Quaderns digitals, n. 54, 2008. Disponible en: <http://www.quadernsdigitals.net/ index.php?accionMenu=hemeroteca.VisualizaArticulolU.visualiza\&articulo id=10725>. Acceso en: 5 jun. 2014.

GARCÍA FERRANDO, Manuel. Postmodernidad y deporte: Entre la individualización y la masificación: encuesta sobre hábitos deportivos de los españoles, 2005. Madrid: Consejo Superior de Deportes, 2006.

GARRETA, Nuria; CAREAGA, Pilar. Modelos masculino y femenino en los textos de E.G.B. Madrid: Instituto de la Mujer, 1987. (Serie Estudios, n. 14).

GONZÁLEZ-PALOMARES, Alba; REY-CAO, Ana. Cultura corporal y estereotipos en las imágenes de libros de texto de educación física publicados bajo el período de la Ley Orgánica de Educación (LOE). Revista Ágora para la EF y el Deporte, v. 15, n. 1, p. 1-19, ene/abr., 2013.

GONZÁLEZ, Alba; TÁBOAS, María Inés; REY, Ana. Los libros de texto como herramientas para la promoción de una práctica físico-deportiva en igualdad: análisis comparativo de la representación racial entre los libros publicados durante la vigencia de la LOGSE y la LOE. Cuadernos de Psicología del Deporte, n. 10, p. 31-36, 2010.

GONZALEZ, Jose María; CONTRERAS, Onofre; KIRK, David; CARRASCO, María; RODRÍGUEZ PEREA, María. La construcción educativa el estereotipo corporal a través de la educación física. Habilidad Motriz, n. 22, p. 45-50, 2004.

GONZÁLEZ, Marta. ¿Tienen sexo los contenidos de Educación Física Escolar? Transmisión de estereotipos de sexo a través de los libros de texto en la etapa de Secundaria. Revista Internacional de Medicina y Ciencias de la Actividad Física y el Deporte, v. 5, n. 18, p. 77-88, jun. 2005.

HARDIN, Brent; HARDIN, Marie. Distorted pictures: images of disability in physical educational textbooks. Adapted Physical Activity Quarterly, v. 21, n. 4, p. 1543-2777, 2004.

HEINEMANN, Klaus. Introducción a la metodología de la investigación empírica en las ciencias del deporte. Barcelona: Paidotribo, 2003.

INSTITUTO NACIONAL DE ESTADÍSTICA (INE). Revisión del Padrón Municipal 2015. Disponible en: <http://www.ine.es/>. Acceso en: 24 feb. 2016.

ESPAÑA. Jefatura del Estado. Ley Orgánica 1/1990, de 3 de octubre, de Ordenación General del Sistema Educativo (LOGSE). Boletín Oficial del Estado, n. 238, 4 oct. 1990. Disponible en: <https:// www.boe.es/boe/dias/1990/10/04/pdfs/A28927-28942.pdf>. Acceso en: 5 jun. 2014.

ESPAÑA. Jefatura del Estado. Ley Orgánica 2/2006, de 3 de mayo, de educación (LOE). Boletín Oficial del Estado, n. 106, 4 mayo 2006a. Disponible en: <https:/www.boe.es/buscar/pdf/2006/BOEA-2006-7899-consolidado.pdf>. Acceso en: 5 jun. 2014.

ESPAÑA. Real Decreto 1513/2006, de 7 de diciembre, por el que se establecen las enseñanzas mínimas de la educación primaria. Boletín Oficial del Estado, n. 293, 8 dic. 2006b. Disponible en: <https://www.boe.es/boe/dias/2006/12/08/pdfs/A43053-43102.pdf>. Acceso en: 5 jun. 2014.

LÓPEZ, Asunción; LLEDÓ, Ángel Ignacio; JIMÉNEZ, Juan Ramón; CANO, María Isabel; VIERA, Ana María. Piaget en el aula. Cuadernos de Pedagogía, n. 163, p. 20-27, 1988.

LÓPEZ, Cristina; CASTAÑER, Marta. Investigar la lectura de la imagen fija publicitaria con relación al cuerpo y la actividad física. Tándem, n. 21, p. 8-16, 2006. 
LÓPEZ VILLAR, Cristina. El cuerpo que nos venden: sobre la publicidad y los estereotipos corporales relacionados con la actividad física. In: CASTAÑER, Marta (coord.). La inteligencia corporal en la escuela: análisis y propuestas. Barcelona: Graó, 2006. p. 33-50.

LÓPEZ VILLAR, Cristina. El cuerpo deportivo en las imágenes publicitarias de revistas. Madrid: Bubok Publishing, 2011.

LLUCH, Xavier. La multiculturalidad en los libros de texto: invisible, retórica, políticamente correcta, exótica, lejana, racial. Cuadernos de Pedagogía, n. 328, p. 1-8, 2011.

MOLINA, Joan Pere; DEVÍS, José; PEIRÓ, Carmen. Materiales curriculares: clasificación y uso en educación física. Pixel-Bit. Revista de Medios y Educación, n. 33, p. 183- 197, 2008.

MORENO, Montserrat. Cómo se enseña a ser niña: el sexismo en la escuela. Barcelona: Icaria ocho de marzo, 1986.

MOSCOSO, David; MOYANO, Eduardo. Deporte, Salud y Calidad de Vida. Madrid: Fundación La Caixa, 2009. (Estudios Sociales, 26).

MOYA, Irene; ROS, Concepción; BASTIDA, Anabel; MENESCARDI, Cristina. Estereotipos de sexo y raza en las imágenes de los libros de texto de educación física en primaria. Retos. Nuevas tendencias en Educación Física, Deporte y Recreación, n. 23, p. 14-18, 2013.

MOYA-MATA, Irene; ROS, Concepción; MENESCARDI, Cristina. Los contenidos de Educación Física a través de las imágenes de los libros de texto de Educación Primaria. Apunts, v. 118, n. 4, p. 40-47, 2014a.

MOYA-MATA, Irene; ROS, Concepción; MENESCARDI, Cristina; BASTIDA, Anabel. Estereotipos corporales en los libros de texto de Educación Física en Educación Primaria. Habilidad motriz, n. 43, p. 25-32, 2014b.

MOYA-MATA, Irene; RUIZ-SANCHÍS, Laura; ROS, Concepción. Diseño y validación de un instrumento para analizar "las otras imágenes" en los libros de texto de Educación Física. Revista Brasileira de Educação Física Escolar, v. 3, p. 8-22, mar. 2016.

NEUENDORF, Kimberly A. Content analysis: A methodological primer for gender research. Sex Roles, v. 64, n. 3-4, p. 276-289, 2011.

PARRA, Juan. Educación en valores y no sexista. Castilla La Mancha: Instituto de la Mujer, 2009.

PÉREZ, Petra María; SÁNCHEZ, Francesc Josep; ROS, Concepción. Temas de antropología de la educación. Valencia: Tirant lo Blanch, 2011.

PIÑUEL, José Luis. Epistemología, metodología y técnicas del análisis de contenido. Estudios de Sociolingüística, v. 3, n. 1, p. 1-42, 2002.

RAMÍREZ, Gonzalo. Estereotipos corporales en las portadas de los videojuegos de género deportivo. Revista Internacional de Medicina y Ciencias de la Actividad Física y el Deporte, v. 11, n. 42, p. 407-420, 2011.

RAMÍREZ, Tulio. El blanco, el mestizo, el negro y el indio en las ilustraciones de los textos escolares de educación básica en Venezuela. Investigación y postgrado, v. 17, n. 1, p. 47-82, 2002.

REA, Louis; PARKER, Richard Designing and conducting survey research. San Francisco, CA: Jossey-Bass, 2014.

REY-CAO, Ana; TÁBOAS-PAIS, María Inés; CANALES, Inmaculada. La representación de las personas mayoresen los libros de texto de Educación Física. Revista de Educación, n. 362, p. 129153, 2013. 
SÁNCHEZ, Pedro; BÓDALO, Ester. Presencia y ausencia de los mayores en la publicidad televisiva. Revista del Ministerio de Trabajo y Asuntos Sociales, n. 25, p. 19-25, 2000.

SCHARAGRODSKY, Pablo. En la educación física queda mucho género por contar. Revista educación física y ciencia, n. 6, p. 12-22, 2003.

SERRA, Carles; ALEGRET, Joan Luis. La diversidad humana en los libros de texto. Cuadernos de Pedagogía, n. 264, p. 20-23, 1997.

TÁBOAS, María Inés; REY, Ana. El cuerpo en las imágenes de los libros de texto de educación física: análisis de dos editoriales. Kronos, n. 11, p. 10-15, 2007.

TÁBOAS, María Inés; REY, Ana. La deportivización del currículum de educación física en las imágenes de los libros de texto de la ESO. Kronos, n. 16, p. 71-74, 2009.

TÁBOAS, María Inés; REY, Ana. Las imágenes en los libros de texto de Educación Física de la ESO: modelos corporales y actividad física. Revista de Educación, n. 354, p. 293-322, 2011.

TÁBOAS-PAIS, María Inés; REY-CAO, Ana. Gender diferences in physical education textbooks in Spain: a contente analysis of photografs. Sex Roles, v. 67, n. 7-8, p. 389-402, oct. 2012a.

TÁBOAS-PAIS, María Inés; REY-CAO, Ana. Disability in Physical Education Textbooks: an analysis of image content. Adapted Physical Activity Quarterly, n. 29, p. 310-328, 2012b.

TÁBOAS-PAIS, María Inés; REY-CAO, Ana. La representación de las personas mayores en los libros de texto de Educación Física. Revista de Educación, n. 362, p. 129-153, 2012c.

TIRADO, Miguel Ángel. Un culto inculto al cuerpo: una intervención educativa en la ESO. Tándem, $n$. 21, p. 67-73, 2006.

TORRES, Jurjo. Diversidad cultural y contenidos escolares. Revista de Educación, n. 345, p. 83-110, 2008. 